ClinicAl VISTAS

\section{Foot ulcer and osteomyelitis}

A 3I-year-old man from northern Ontario had acute swelling, purpura and pain in his left lateral forefoot region, which increased progressively over to weeks until he became bedridden. A clinical diagnosis of gout was made, but the pain did not improve with NSAIDs. One month later, a small pustule developed that progressed to an ulcer with purulent drainage. On presentation I month later, his left foot was swollen, and the lateral forefoot was exquisitely tender to palpation. A 2-cm ulcer, which probed to bone, was present on the lateral aspect of the foot (Fig. I). The patient was afebrile, and findings on general medical and pulmonary examinations were unremarkable. A plain radiograph of the foot revealed dystrophic calcification in the soft tissues, with osteopenia and periosteal reaction along the fifth metatarsal bone consistent with active osteomyelitis (Fig. 2). The chest radiograph appeared normal.

Intravenous therapy with ciprofloxacin and clindamycin was started empirically. Staphylococcus aureus and Streptococcus agalactiae (group B streptococcus) were recovered from the deep wound swab. The patient's condition did not improve after a week of parenteral antibacterial therapy. Surgical débridement revealed a pocket of grossly necrotic tissue that had replaced part of the fifth metatarsal. Histologic examination revealed broadbased budding yeast consistent with Blastomyces dermatitidis (Fig. 3). The antibiotic therapy was replaced by treatment with amphotericin B (40 mg intravenously once daily) for I week followed by itraconazole (400 mg orally once daily) to complete a I2-month course. The patient had prompt relief of pain, with healing of the wound and radiographic evidence of bone reconstitution occurring within 6 months.

Blastomycosis is an uncommon granulomatous systemic fungal infection caused by the thermally dimorphic fungus $B$. dermatitidis. ${ }^{1}$ Areas in North
America in which this fungus is endemic include the Ohio and Mississippi River basins and the regions that border the Great Lakes. ${ }^{1}$ The annual incidence of blastomycosis is greater in the district of Kenora, Ont., than in all of Manitoba (7.I v. 0.6 cases per 100000 people). ${ }^{2}$

$B$. dermatitidis exists in a mycelial form in the soil, but when disturbed, the released conidia are inhaled and con- verted to thick-walled budding yeasts that cause respiratory infection and hematogenous dissemination producing extrapulmonary disease. ${ }^{2}$ The median incubation period is $30-45$ days. Pulmonary disease may be acute or chronic and can mimic infection from other fungi, malignant disease or infection from pyogenic bacteria or Mycobacterium tuberculosis. Extrapulmonary
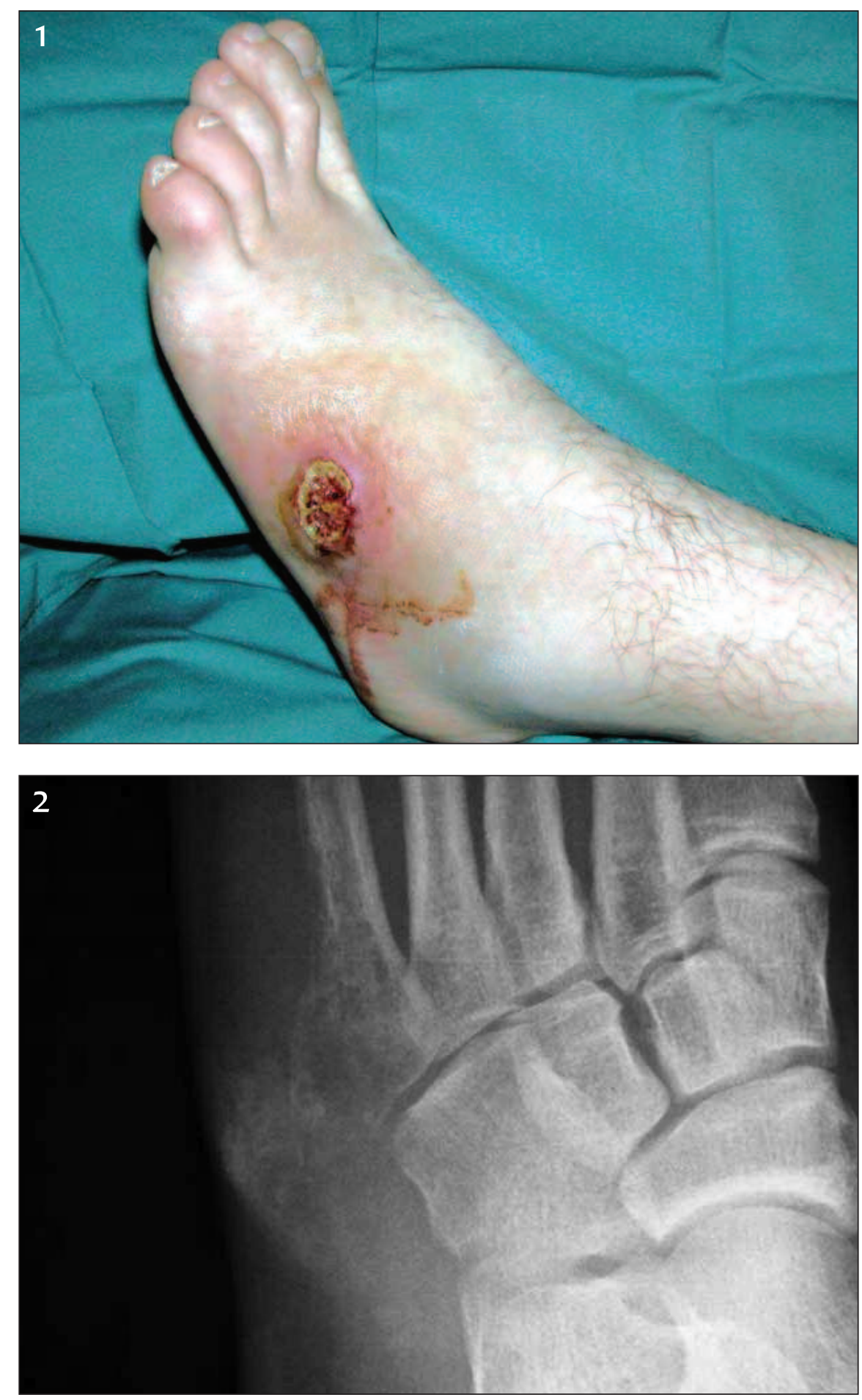


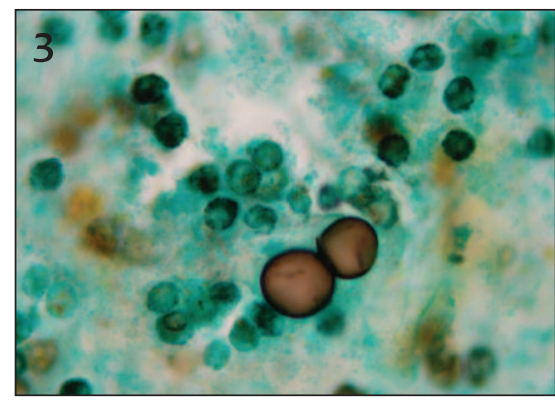

sites most commonly involve the skin, bone and genitourinary system ${ }^{1}$ and occur most likely at the time of the primary infection, with potential for later relapse.

Patients with blastomycosis osteomyelitis most frequently present with pain and swelling of the affected area, often accompanied with an overlying skin abscess. ${ }^{1}$ Most cases respond to treatment with antifungal drugs (amphotericin B and agents from the azole class), but some may also require surgical débridement. ${ }^{3}$ Blastomycosis was suspected in our patient because of his history of residence in an area where the fungus is endemic, an unusual protracted course and an atypical location of the foot lesion. Furthermore, he did not have evidence of the more common causes of ulcers on the lower extremities, such as diabetic neuropathy (ulcer on weight-bearing surface, or areas of bony or shoe pressure), venous stasis disease (leg ulcer and venous stasis changes), gout (ulcer adjacent to joints and tophaceous debris) or lymphedema (ulcer with serous drainage and diffuse limb swelling).

\section{John M. Embil}

Departments of Medicine

and Medical Microbiology

University of Manitoba

\section{John L. Wiens}

Department of Orthopedics

Seven Oaks General Hospital

Mark Oppenheimer

Faculty of Medicine

University of Manitoba

Elly Trepman

Departments of Medical Microbiology and Surgery

University of Manitoba

Winnipeg, Man.

\section{REFERENCES}

I. Chapman SW. Blastomyces dermatitidis. In: Mandell CL, Bennell JE, Dolin R, editors. Principles and practice of infectious diseases. 6th ed. Philadelphia: Churchill Livingston; 2005. p. 3027-40.

2. Crampton TL, Light RB, Berg GM, et al. Epidemiology and clinical spectrum of blastomycosis diagnosed at Manitoba hospitals. Clin Infect Dis 2002; 34:I310-6.

3. Chapman SW, Bradsher RW Jr, Campbell GD Jr, et al. Practice guidelines for the management of patients with blastomycosis. Infectious Diseases Society of America. Clin Infect Dis 2000;30:679-83.

\section{IN THE LITERATURE}

\section{Trastuzumab (Herceptin) and HER2-positive breast cancer}

Piccart-Gebhart MJ, Procter M, Leyland-Jones B, et al. Trastuzumab after adjuvant chemotherapy in HER2positive breast cancer. $N$ Engl J Med 2005;353:1659-72.

Background: HER2 (human epidermal growth factor receptor 2) is present in I5\%-25\% of breast cancers. Women with HER 2-positive breast cancer usually have more aggressive cancer, are at increased risk of recurrence and have a poorer survival than other women with breast cancer. Trastuzumab, a recombinant monoclonal antibody, acts against HER2 receptors.

Design: In this international randomized trial, women who had undergone surgical excision of a HER2-positive, early invasive breast cancer and who had completed 4 or more courses of chemotherapy were randomly assigned to receive trastuzumab every 3 weeks or observation alone (control group) for I or 2

Table 1: Outcomes of 4 trials of trastuzumab therapy for HER2-positive breast cancer

\begin{tabular}{|c|c|c|c|c|c|}
\hline Study & ARR, \% & NNT & $\begin{array}{c}\text { Absolute } \\
\text { increased } \\
\text { risk of } \mathrm{CHF}, \%\end{array}$ & $\begin{array}{l}\text { No. needed } \\
\text { to cause } 1 \\
\text { case of } \mathrm{CHF}\end{array}$ & $\begin{array}{l}\text { Absolute } \\
\text { increased } \\
\text { survival }\end{array}$ \\
\hline $\begin{array}{l}\text { Piccart-Gebhart } \\
\text { et al }\end{array}$ & $5.5^{*}$ & 18 & 1.7 & 60 & $\begin{array}{l}\text { No significant } \\
\text { improval }\end{array}$ \\
\hline Romond et al ${ }^{1}$ & $11.8^{*}$ & 8.5 & $3 \dagger$ & 30 & $2.5 \%$ at $3 \mathrm{yr}$ \\
\hline Marty et $\mathrm{al}^{2}$ & $5 \neq$ & 20 & $9 \S$ & 11 & $\begin{array}{l}4 \% \text { at cut-off } \\
\text { (about } 3 \text { yr) }\end{array}$ \\
\hline Slamon et $\mathrm{al}^{3}$ & 59 & 20 & 8 & 13 & $11 \%$ at $1 \mathrm{yr}$ \\
\hline
\end{tabular}

Note: HER2 = human epidermal growth factor receptor 2, ARR = absolute risk reduction, NNT = number needed to treat, $\mathrm{CHF}=$ congestive heart failure.

*Refers to disease-free survival, including no recurrence, death, new cancer [breast or other] †New York Heart Association class III or IV CHF.

$\ddagger$ Refers to complete tumour response, assessed by radiologic and visual inspection.

$\S$ Asymptomatic decrease in left ventricular ejection fraction of $\geq 15 \%$.

IRefers to complete tumour response (no tumour seen), assessed by radiologic or clinical examination.

years. Patients were included if they had adequate liver, kidney and bone marrow function and a normal left ventricular ejection fraction (LVEF). Women were excluded if they had metastases, prior invasive breast cancer, another neoplasm, or a cardiac condition such as angina pectoris requiring medication, uncontrolled hypertension or prior congestive heart failure or myocardial infarction. The primary outcome measure was disease-free survival; secondary end points were cardiac safety, overall survival, time to distant occurrence and site of first disease-free survival event.

Results: The results presented were from an interim analysis of data for women who had been followed for I year (I694 in the trastuzumab group, I693 in the control group). Events (recurrences, new cancer [breast or other], death) were half as common in the treatment group as in the control group (hazard ratio 0.54 , 95\% confidence interval $0.43-$ o.67), although there was no improve- 